\title{
ESTRATÉGIAS PARA ADAPTAÇÃO DE LODO AERÓBIO MESOFÍLICO PARA TERMOFÍLICO UTILIZANDO EFLUENTE DE CELULOSE BRANQUEADA KRAFT
}

\author{
R. Y. CABRERA-PADILLA ${ }^{1,2}$, E. C. PIRES ${ }^{3}$. \\ ${ }^{1}$ Universidade Tiradentes, Programa de Pós-graduação de Engenharia de Processos \\ ${ }^{2}$ Instituto de Tecnologia e Pesquisa \\ ${ }^{3}$ Escola de Engenharia de São Carlos/USP, Departamento de Hidráulica e Saneamento.
}

RESUMO - O presente trabalho tem como objetivo a adaptação de lodo aeróbio mesofílico para termofílico em reator aeróbio, utilizando efluente de celulose branqueada Kraft fornecida pela fabrica de papel e celulose Ripassa S.A. LimeiraSP. Para tal propósito foram utilizadas duas estratégias de alimentação, o reator $\mathrm{R} 1$ foi alimentado com substrato de branqueamento, enquanto que o reator R2 inicialmente foi alimentado com substrato sintético e posteriormente à adaptação de lodo foi realizada a troca gradual por substrato de branqueamento. Ambos os reatores foram operados em batelada a $55^{\circ} \mathrm{C}$ de temperatura. Neste trabalho, ambas as estratégias foram avaliadas quanto a $\mathrm{pH}$, demanda química de oxigênio (DQO), sólidos solúveis totais (SST), sólidos solúveis voláteis (SSV), e análises microbiológicos, observando-se que a segunda estratégia apresentou uma ligeira vantagem na degradação de DQO e principalmente uma considerável produção de biomassa em comparação com a primeira estratégia.

\section{INTRODUÇÃO}

Tratamento termofílico aeróbio é um processo único e relativamente novo para o tratamento de águas residuais com altas temperaturas e cargas orgânicas. A eficiência da tecnologia do processo termofílico depende de factores relacionados com o sistema microbiologia, mantenimento da estabilidade do sistema e uso de um inoculo que é capaz de crescer em temperaturas elevadas. Algumas das vantagens de tratamento aeróbio termofílico incluem as altas taxas de degradação e a rápida inactivação de microrganismos patogénicos. As altas taxas de degradação reduzem o tempo de detenção necessário para o tratamento e, conseqüentemente, a instalação e diminuição dos custos operacionais (Tripathi e Allen, 1999).

Nesta pesquisa enfatizou-se a aplicação para águas residuárias de indústrias de papel e celulose, cujas principais características são a alta toxicidade e a baixa biodegradabilidade devido à presença de taninos, ligninas, resinas e compostos clorofenólicos. A composição destes efluentes, que tem uma grande influência sobre o tratamento, pode variar 
consideravelmente dependendo da matéria-prima, do processo de polpação e tipo de branqueamento, a lavagem, o grau e tipo de tratamento interno e externo dos filtrados (Kortekaas et al., 1998; Vidal et al., 2001)

De acordo com Sierra-Alvarez (1990) e Vidal et al., (2001) os processos de polpação, que removem a lignina e seus derivados, são os principais responsáveis pela elevada coloração, além da difícil degradação biológica do efluente. Segundo Rosa e Nolasco (1994), o branqueamento sozinho, pode chegar a ser o responsável por valores superiores a $60 \%$ da carga orgânica do efluente da indústria.

Os efluentes dessas indústrias possuem temperaturas elevadas, da ordem de $55^{\circ} \mathrm{C}$ a 60 ${ }^{\circ} \mathrm{C}$, o que gera a necessidade de sua refrigeração, resultando em custos adicionais. Diante disto, o Departamento de Hidráulica e Saneamento - EESC-USP em colaboração com outras instituições, vem desenvolvendo várias pesquisas com objetivo de se estudar a viabilidade técnica do tratamento biológico termofílico.

Tripathi e Allen (1999) realizaram a adaptação do lodo aeróbio mesofílico para termofílico utilizando-se efluente de polpa branqueada kraft. Eles aumentaram gradualmente a temperatura iniciando-se em $35^{\circ} \mathrm{C}$ e atingindo posteriormente $45^{\circ} \mathrm{C}, 55^{\circ} \mathrm{C}$ e finalmente $60^{\circ} \mathrm{C}$ durante um período de 8 semanas.

Carmo (2004) fez a adaptação de lodo aeróbio utilizando substrato sintético de polpa celulósica, utilizando duas estratégias para este propósito, inicialmente fez a adaptação com aumento gradativo da temperatura de $35^{\circ} \mathrm{C}$ para $57^{\circ} \mathrm{C}$ e sem aumento gradativo de temperatura, fixando a temperatura desde o início em $57^{\circ} \mathrm{C}$.

Megda (2007) optou por realizar a adaptação do lodo aeróbio sem aumento gradativo de temperatura, fixando desde o início a temperatura em $55^{\circ} \mathrm{C}$, utilizando água residuária de indústria de celulose não-branqueada. $\mathrm{O}$ período de adaptação foi de mais de 3 meses.

Baseada nas pesquisas anteriores o presente trabalho tem como objetivo a adaptação de lodo aeróbio mesofílico para temperatura termofílica de $55^{\circ} \mathrm{C}$, utilizando água resíduária de indústria de celulose branqueada kraft.

\section{MATERIAL E MÉTODOS}

\subsection{Caracterização do Efluente}

O efluente utilizado nesta pesquisa foi de celulose branqueada Kraft fornecida pela fabrica de papel e celulose Ripassa S.A. Limeira-SP, inicialmente este efluente foi caracterizado quanto a DQO, DBO, nitrogênio, fosforo e cor. 


\subsection{Estratégias de adaptação}

Para a adaptação de lodo aeróbio mesofílico foram utilizadas duas estratégias, cujas metodologias experimentais serão descritas a seguir:

Estratégia I: Para este ensaio foi utilizado um reator (R1) com capacidade de 1L, alimentado com um efluente constituído pela mistura de $60 \%$ de substrato de branqueamento ácido mais $40 \%$ de substrato de branqueamento básico, também foi adicionado nitrogênio e fósforo, em quantidade suficiente para manter a relação DQO:N:P em 300:5:1. Além disso, foi adicionado $1 \mathrm{ml} . \mathrm{L}^{-1}$ de nutrientes composto por: Solução de cloreto férrico, solução de cloreto de cálcio, solução de sulfato de magnésio e solução amortecedora de fosfato. $\mathrm{O}$ reator foi operado em temperatura de $55^{\circ} \mathrm{C}$.

Estratégia II: Para este ensaio também foi utilizado um reator (R2) com capacidade de 1L de capacidade. Neste caso, para a alimentação do reator foi utilizado um substrato sintético contendo sacarose, amido, fósforo, nitrogênio e $0,42 \mathrm{~g} . \mathrm{L}^{-1}$ de extrato de carne, resultando em uma DQO total próxima do valor obtido com o substrato de branqueamento da primeira estratégia $(2637 \mathrm{mg} / \mathrm{L})$. Posteriormente à adaptação de lodo foi realizada a troca gradual por substrato de branqueamento preparado da mesma maneira que na estratégia I. O reator também foi operado em temperatura de $55^{\circ} \mathrm{C}$.

Ambos os reatores foram preenchidos com $0,4 \mathrm{~L}$ de lodo aeróbio e $0,6 \mathrm{~L}$ de substrato e operados em batelada com um tempo de detenção hidráulica (TDH) de 5 dias, sendo a cada 24 horas trocado 0,2 L de licor misto (LM) por novo substrato, e o pH ajustado para 7,0.

\subsection{Parâmetros Monitorados}

Foram monitorados os seguintes parâmetros ao longo da adaptação do lodo mesofílico para termofílico: $\mathrm{pH}$, DQO, SST e SSV. Para análise de DQO, SST e SSV foram retiradas amostras do licor misto (LM), após 10 minutos de sedimentação, três vezes por semana. Todas as análises físico-químicas foram realizadas de acordo com APHA (1998). Também foram realizadas análises microbiológicas, com amostras retiradas uma vez por mês. 


\section{RESULTADOS E DISCUSSÃO}

\subsection{Caracterização do Efluente}

Na Tabela 1 apresentam-se os resultados da caracterização do substrato de branqueamento kraft utilizado para adaptação de lodo aeróbio.

Tabela 1 - Valores dos parâmetros do afluente de branqueamento kraft

\begin{tabular}{|c|c|}
\hline Parâmetros & Valores \\
\hline DQO $\left(\mathrm{mg} . \mathrm{L}^{-1}\right)$ & 2627 \\
\hline DBO $\left(\mathrm{mg} . \mathrm{L}^{-1}\right)$ & 1090 \\
\hline Nitrogênio $\left(\mathrm{mg} . \mathrm{L}^{-1}\right)$ & 5,4 \\
\hline Fósforo $\left(\mathrm{mg} \cdot \mathrm{L}^{-1}\right)$ & 0,897 \\
\hline Cor $(\mathrm{UC})$ & 1350 \\
\hline
\end{tabular}

\subsection{Adaptação de lodo aeróbio mesofilo para termofilo}

Depois de 95 dias de operação foi conseguida a adaptação de lodo aeróbio mesofílico para termofílico para ambas as estratégias.

$\mathrm{Na}$ Figura 1 apresenta-se os valores do $\mathrm{pH}$ ao longo do tempo de adaptação de lodo aeróbio para os dois reatores, onde pode ser observado que para $\mathrm{R} 1 \mathrm{o} \mathrm{pH}$ teve um aumento considerável nos primeiros 10 dias de operação atingindo valores próximo de 9,0 . O tempo restante da adaptação o pH se manteve oscilando entre 8,0 a 8,5. Para R2 o comportamento deste parâmetro foi diferenciado para as duas etapas de adaptação. Na primeira etapa, durante o tempo que o reator foi alimentado somente com substrato sintético, o pH variou de 6,5 a 8,2 . A partir do momento que foi iniciada a troca gradativa com substrato de branqueamento ou segunda etapa, o pH teve uma tendência a aumentar até chegar aproximadamente a 9,0. Acredita-se que isto aconteceu devido ao choque sofrido pelo sistema ao ser alimentado com um substrato muito mais complexo. 


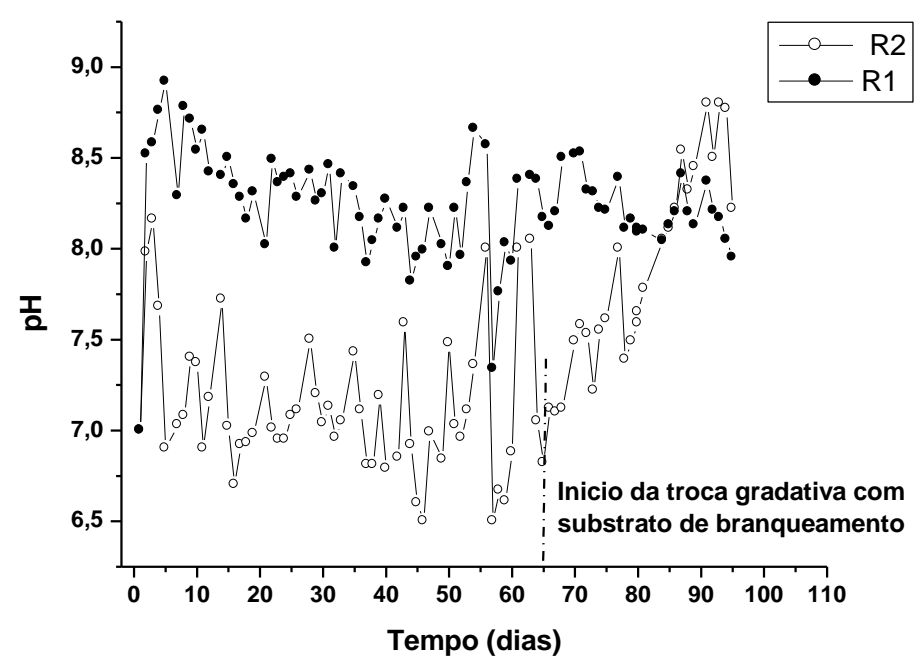

Figura 1 - Valores do pH ao longo do tempo durante a adaptação de lodo aeróbio para as duas estratégias estudadas.

Mostram-se na Figura 2 os valores da DQO determinados ao longo do tempo durante o período de adaptação de lodo aeróbio para os dois reatores. Como pôde ser observado nos primeiros 65 dias de operação, ambos os reatores apresentaram tendências semelhantes, diferenciando-se pela maior degradação de DQO atingida pela Estratégia II (R2) em comparação com a estratégia I (R1). Nesse ponto que foi iniciada a troca gradativa de substrato sintético por branqueamento para R2 a DQO apresentou uma tendência de aumento de valor da concentração de DQO próximo do valor atingido por R1 no final do período de adaptação.

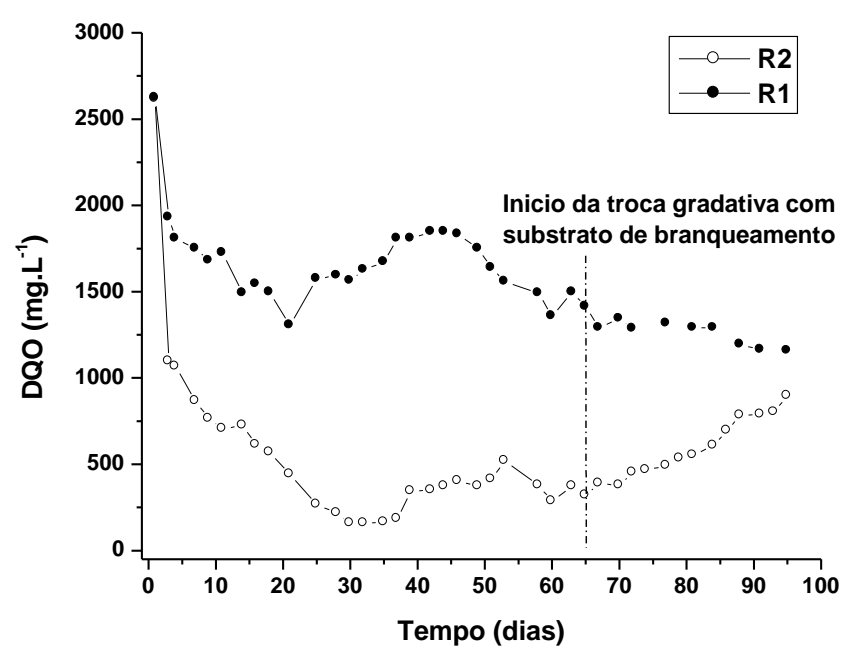

Figura 2 - Valores da DQO determinados ao longo do tempo durante a adaptação do lodo aeróbio para as duas estratégias estudadas. 
Nas Figuras 3 e 4 apresentam-se os valores dos SST e SSV determinados ao longo do tempo de período de adaptação de lodo aeróbio para as estratégias R1 e R2 respectivamente, Observaram-se comportamentos semelhantes para ambos os parâmetros. Na Figura 4 onde esta representada a biomassa (SSV), pode ser observado inicialmente para ambas as estratégias, perda considerável de biomassa no efluente, devido provavelmente ao choque térmico sofrido pelos microrganismos. Depois desse período inicial, a quantidade de biomassa se manteve praticamente constante para R1 até o final do período de adaptação, enquanto que para R2 após o período inicial a biomassa mostrou uma tendência de crescimento até o início da troca gradativa com substrato de branqueamento. A partir desse ponto a biomassa diminuiu consideravelmente, um processo provocado talvez pelos compostos tóxicos presentes no substrato de branqueamento.

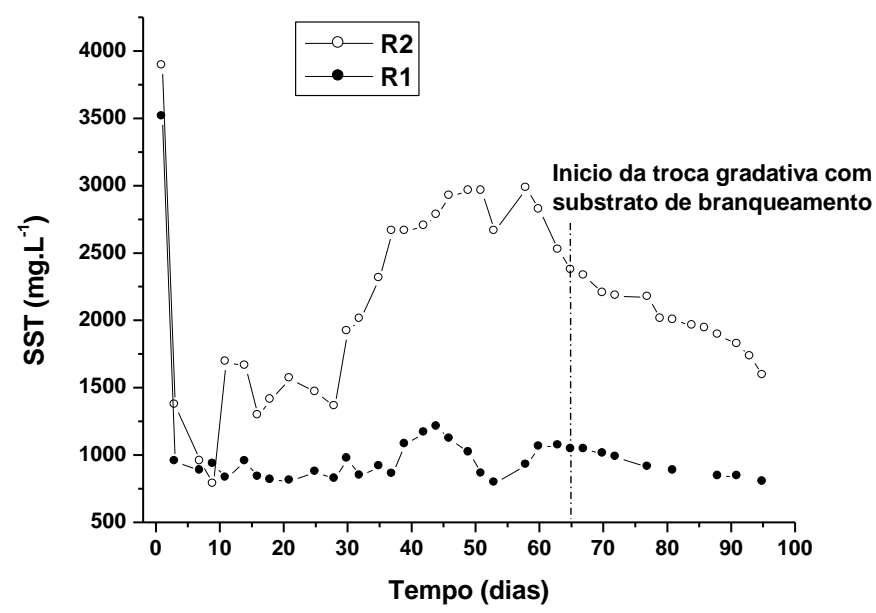

Figura 3 - Valores dos SST determinados ao longo do tempo durante a adaptação de lodo aeróbio para as duas estratégias estudadas.

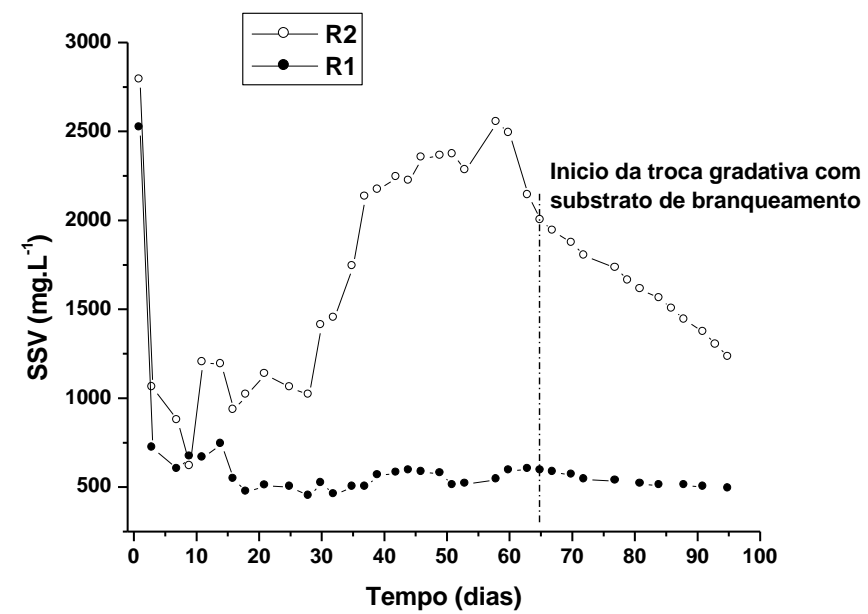

Figura 4 - Valores dos SSV (biomassa) determinados ao longo do tempo durante a adaptação de lodo aeróbio para as duas estratégias estudadas. 
Nas Figuras 5 e 6 mostram-se os microrganismos da biomassa formada durante a adaptação de lodo por um período de 3 meses para os dois reatores. Como pode ser observado na Figura 5, que corresponde ao R1 tem-se uma menor quantidade de microrganismos filamentosos e maior quantidade de material inerte em comparação com R2 (Figura 6). Este fato pode explicar a maior facilidade de sedimentação da primeira estratégia em comparação com a segunda.

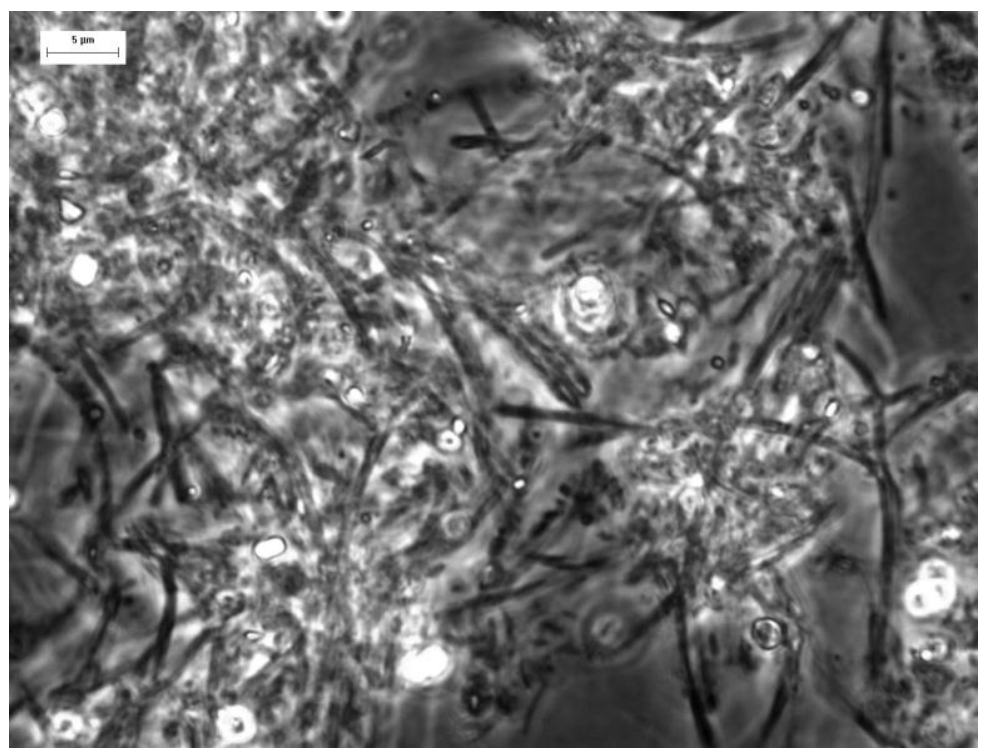

Figura 5 - Biomassa formada no período de adaptação do lodo aeróbio no R1 (estratégia I).

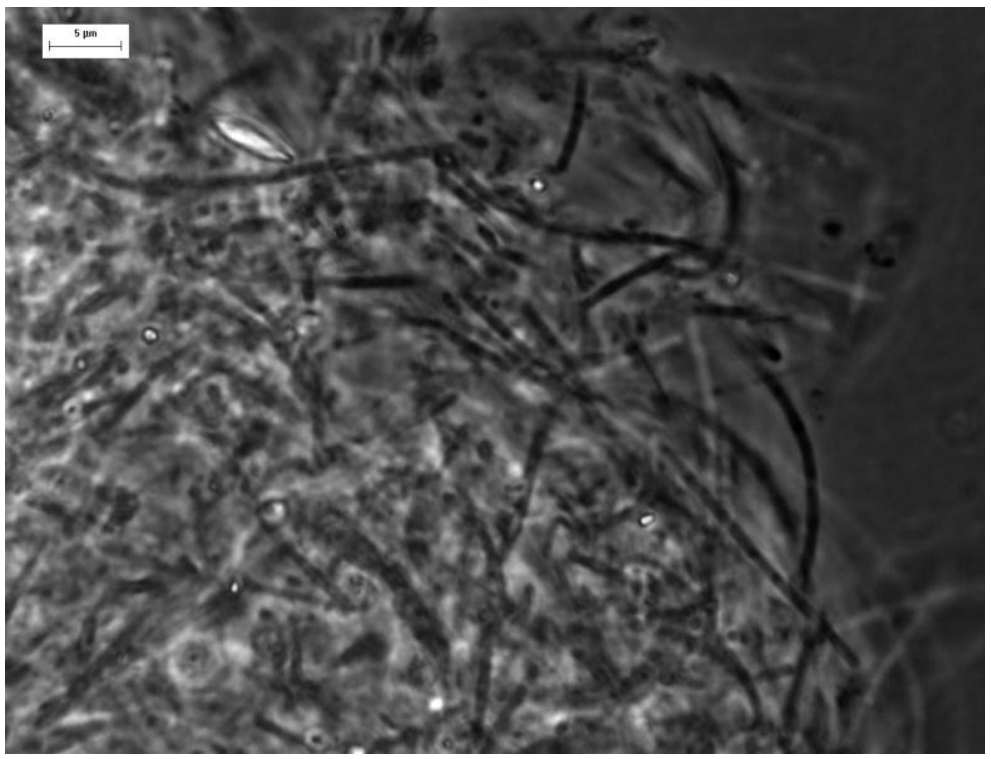

Figura 6 - Biomassa formada no período de adaptação do lodo aeróbio no R2 (estratégia II). 


\section{CONCLUSÃO}

Verificou-se que para este tipo de substrato (água residuária de indústria de celulose branqueada kraft) a melhor estratégia para adaptação de lodo aeróbio mesofílico para termofílico consiste em realizar primeiramente a adaptação com substrato sintético e posteriormente realizar troca gradativa com substrato de branqueamento, conseguindo-se assim a formação de uma quantidade maior de biomassa, apesar da dificuldade oferecida na sedimentação.

\section{REFERÊNCIAS}

Carmo, D.F. Tratamento Biológico Termofílico de Efluente Sintético de Polpa Celulósica Através do Processo Combinado Anaeróbio Aeróbio. Tese de doutorado. Escola de Engenharia de São Carlos, Universidade de São Paulo. São Carlos, 2004.

Kortekaas, S.; Vidal, G.; Yan-Ling, H.; Lettinga, G.; Field, J. A. Anaerobic-Aerobic Treatment of Toxic Pulping Black Liquor with Upfront Effluent Recirculation. J. Ferment. Bioeng., v. 86, p. 97-110, 1998.

Megda, C. R. Filtro Anaeróbio Ascendente Combinado com Reator Aeróbio de Lodos Ativados em Batelada no Tratamento de Águas Residuárias Sintéticas de Indústria de Polpa Celulósica não Branqueada sob Condições Termofílicas. Tese de doutorado. Escola de Engenharia de São Carlos, Universidade de São Paulo. São Carlos, 2007.

Rosa, J; Nolasco, M.A. Physical-Chemical and Toxicological Characterization of na Integrated Pulp and Paper Industry". In: I Simpósio Latino-Americano de Saúde de Ecossistemas Aquáticos, Ecológico de Bioensaios. São Carlos-SP. 1994.

Sierra-Alvarez, R. The Role of Natural Wood Constituents on The Anaerobic Treatabillity of Forest Industry Wastewaters. Tese (Doutorado) - Wageningen, Netherlands 1990.

Standard Methods for the Examination of Water and Wastewater 20 th ed. American Public Health Association / American Water Works Association / Water Pollution Control Federation, Washington, DC, USA, 1998.

Tripathi, C. S.; Allen, D. G. Comparison of Mesophilic and Thermophilic Aerobic Biological Treatment in Sequencing Batch Reactors Treating Bleached Kraft Pulp Mill Effluent. Water Res., v. 33, p. 836-846, 1999.

Vidal, C. M. S. Microfiltração Tangencial como Alternativa de Pós-Tratamento de Efluente de Reator Anaeróbio de Leito Expandido Alimentado com Esgoto Sanitário. Dissertação (mestrado). Escola de Engenharia de São Carlos, Universidade de São Paulo, 2001. 